\title{
Assessment differentiation degree cryptic species of the genus Apodemus in the Northern Caucasus based on non- metric cranial characters
}

\author{
Albina Amshokova*, Fatimat Tembotova, Ekaterina Kononenko \\ Tembotov Institute of Ecology of Mountain Territories of Russian Academy of Science, 360051 Nalchik, Russia
}

\begin{abstract}
A phenetic analysis of non-metric cranial traits of two genetically identified cryptic species of the genus Apodemus in different ecological conditions of the North Caucasus was carried out. The maximum distance obtained between cryptic species did not exceed the level of subspecies differences. The phenetic distance between A. uralensis and A. flavicollis, which inhabit symbiotopically and sympatrically in the Western Caucasus, is almost 2 times lower. The smaller value of phenetic differences is probably related to the habitat of both species in similar landscapebiotopic and climatic conditions, which contributes to the development of phenotypic similarity. In general, the obtained results indicate weak morphological differentiation of the studied species according to the studied phenetic characters (cranial foramen), although according to the results of molecular genetic analysis of the $c y t b$ gene site, the genetic distance between the studied taxa is $10 \%$ and corresponds to the level of interspecific differences. Based on the above, reliable diagnosis of the studied species in the Caucasus is possible only by molecular genetic methods.
\end{abstract}

\section{Introduction}

The development of criteria for distinguishing cryptic species similar in morphology, karyology, and behavior with overlapping habitats is one of the topical problems of biology. Such studies are especially necessary in the Caucasus mountainous regions to adequately assess the level of biodiversity and its conservation. On the other hand, the study of the Caucasus fauna is complicated by the significant number of twin species, which makes it difficult to study the morphological, physiological, behavioral, ecological, and other features of the problem groups. The representatives of the genus Apodemus, characterized by weak morphological isolation, are among them in the Caucasus. In turn, the need to study cryptic species is determined by a number of reasons. First, it is obvious that without accurate identification of the object of research and the status of its stay in a particular territory, information about it in the vast majority of cases, is not of significant interest (cited from Koblik et al., 2006; p. 7) [1]. Secondly, the inability to identify biologically important species leads to incorrect assessments of the state of bioresources and creates false ideas about biodiversity. It is worth noting that the knowledge of how many species and how they are dispersed largely determines the understanding of biogeographic processes and opens up new opportunities for studying the mechanisms of speciation and dispersal of closely related species (cited from N.M. Sukhikh, 2013) [2].

At present, the issues of differentiation of cryptic species are successfully clarified using a set of methodological approaches, the main component of which is molecular genetic analysis. Using molecular genetic methods, a number of questions concerning representatives of g. Apodemus Caucasus have been solved [3-14]. The results of studies of wood mice from the Western and Central Caucasus using molecular genetic methods showed that the Central Caucasus is inhabited by genetically homogeneous animals, while the Western Caucasus is inhabited by two genetically highly divergent lines of wood mice, one of which shows high genetic similarity with the Central Caucasus mice [15, 16]. Another promising approach may be phenetic analysis [17, 18], based on the use of phene frequencies of threshold non-metric traits [19-22]. It has been shown that using homologous phenes of non-metric traits can also be applied to estimate the level of epigenetic divergence of closely related species [23].

The aim of the study was to assess the degree of morphological differentiation of two cryptic rodent species of Apodemus by non-metrical features of the skull in the conditions of the North Caucasus.

\section{Study area}

The studies were conducted in different ecological conditions in the Western, Central and Eastern Caucasus. The Western Caucasus, according to A.K. Tembotov typification [24-25] belongs to the Kubanskiy variant of the vertical zonation. Within the Kuban variant, the studies covered the following geographical points of Adygea Republic: the Upper Lagonaki plateau (middle mountains), the village of Khamyshki (foothills) and

*Corresponding author: h.a.amshokova@mail.ru 
Krasnodar krai: the Golovinka settlement (the western steppe of the Caucasus plains). Taking into account the biotopic features of the Lagonaki Plateau, it was conditionally divided into two sections - Lower and Upper Lagonaki. Such a division is also related to the fact that, according to the results of molecular genetic analysis, only one species of $A$. uralensis occurs in the Lower Lagonaki Plateau area, whereas both A. uralensis and A. flavicollis species are found in the Upper Lagonaki Plateau area. In the Central Caucasus (KabardinoBalkarian Republic) material was collected in the conditions of the Terskiy variant of the vertical zonation, covering also two altitudinal levels: mid-mountain (around the village of Bezengi) and foothills (around the city of Nalchik (Dolinsk)). The study area (Republic of Dagestan, the vicinity of Bilbil-Kazmalyar village) in conditions of the eastern part of the North Caucasus belongs to the semideserted zone of the Eastern CisCaucasus (Sokolov and Tembotov, 1989) and covers semi-deserts of the south-eastern part of the Caspian lowlands of the Dagestanskiy variant of the vertical zonation.

\section{Materials and methods}

Genetically dated material was used to analyze nonmetric cranial features of cryptic species of wood mice, $A$. uralensis and A. flavicollis, inhabiting the Western (vicinity of Upper Lagonaki plateau $-1756 \mathrm{~m}$ above sea level, vicinity of Khamyshki village - $604 \mathrm{~m}$ a.s.l., vicinity of Golovinka village - $78 \mathrm{~m}$ a.s.1.), Central (vicinity of Besengi village $-1500 \mathrm{~m}$ a.s.l., vicinity of Nalchik (Dolinsk botanical garden - $592 \mathrm{~m}$ a.s.1.) and Eastern Caucasus (vicinity of Bilbill-Kazmalyar village $25 \mathrm{~m}$ a.s.1.). A total of 113 specimens of A. uralensis skulls and 94 specimens of A. flavicollis skulls were studied. The relative age of the animals was determined by the degree of erosion of molar teeth.

During phenetic analysis (isolation, description of phenes, and processing of results), the methods developed by A.G. Vasil'ev $(1996,2005)$ [26-27] were used. The phenotypes were searched and counted using a Carl Zeiss microscope (Stemi 2000C). Most of the phenes used in the work were taken from literature sources [26, 28-29]. The latinized phene coding system developed by I.A. Vasil'eva [30] was taken as the basis. The correlation of phenotypic manifestations with gender, age, and each other was assessed based on the calculation of nonparametric Spearman correlation coefficients. The traits that showed a strong significant correlation with the above factors were excluded from further analysis, which reduces the probability of obtaining artifacts due to bias in the estimates due to the above causes and increases the reliability of indirect genetic interpretation of phenetic differences [27]. A list of the 16 traits remaining after the primary culling is given in Table 1 , and their location is shown in Figure 1.

Phenetic distances as the mean measure of divergence (MMD) within and between populations and their mean standart deviations (MSD) were calculated according to
Hartman [22]. The differences were considered significant at $p<0.05$ and $\mathrm{MMD}>2 \mathrm{MSD}$. The mean measure of uniqueness (MMU) for populations or different samples from the same population was calculated as the sum of MMDs between a given sample and all other samples divided by the number of the pairs of samples compared [18]. We processed the result statistically with Phen 3.0 [31] and STATISTICA 10 software packages.

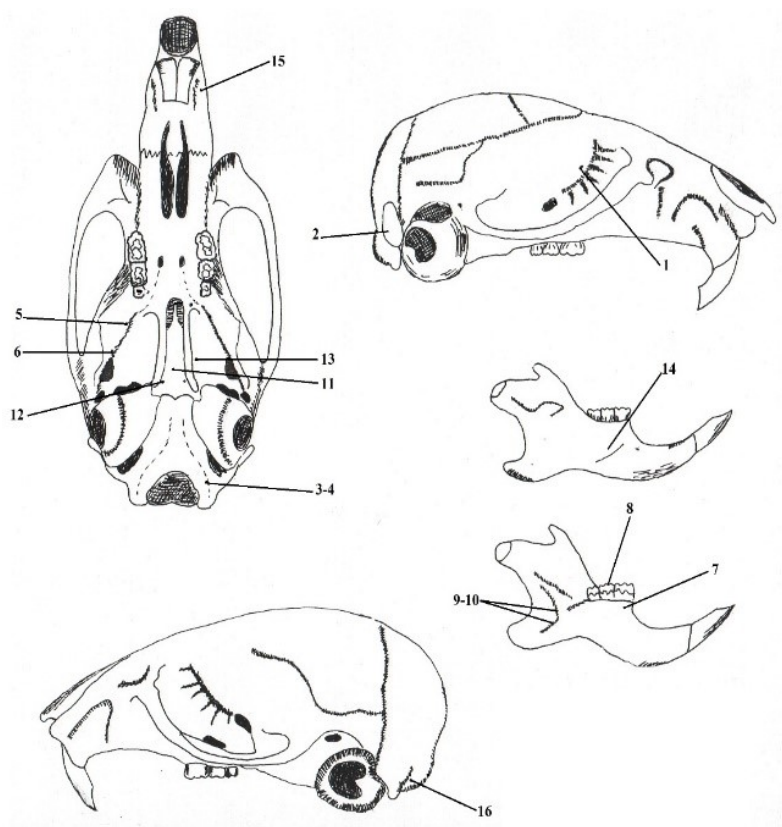

Fig. 1. Phenes of non-metric skull characters in wood mice: 1. duplicate ethmoidal foramen (FEtdu); 2. foramen in the mastoid bone (FEMs); 3. single hypoglossal foramen (FHgsi); 4. triplicate hypoglossal foramen (FHgtr); 5. triplicate foramen in the region of foramen rotundum (FRDtr); 6. duplicate foramen between foramen ovale and foramen rotundum (FLTIdu); 7. single foramen on the lingual side of $\mathrm{M}_{1}$ alveolus (FMtlg); 8. single foramen in the region of $\mathrm{M}_{2}$ on the lingual surface $\left(\mathrm{FPC}\left(\mathrm{M}_{2}\right)\right)$; 9. additional mandibular foramen in the region of angular notch (FMbac); 10. the absence of mandibular foramen in the region of angular notch (FMbac(-)); 11. foramen in the medial part of the sphenoid bone (FBsme); 12. lateral foramina on the ventral surface of the sphenoid bone (FBsla); 13. duplicate alisphenoid foramen (FAsac); 14. single foramen in the masseteric area of the mandible above linea oblique (FMas); 15. single lateral premaxillary foramen (FPmla); 16. single foramen in the condylar fossa of the occipital bone (FFsOcsi).

\section{Results and discussion}

Intraspecific differentiation of $\boldsymbol{A}$. uralensis.

When comparing two Western Caucasian samples of $A$. uralensis originating from different altitudinal levels (vicinity of the Upper Lagonaki plateau and vicinity of the village of Khamyshki) reliable differences were revealed in the frequency of three characters - FLTIdu, FMtlg and FPmla, of which the first two are significantly more frequent in the sample from the village of Khamyshki, and FPmla in the sample from the Upper Lagonaki plateau (tab. 1). 
Table 1. Frequencies of non-metric phenes in A. uralensis in the Western and Central Caucasus

\begin{tabular}{|l|c|c|c|l|l|l|l|l|l|l|}
\hline & WC & WC & CC & \multicolumn{1}{|c|}{ CC } & \multicolumn{6}{|c|}{$\chi^{2}$} \\
\cline { 2 - 13 } & 1 & 2 & 3 & 4 & $1-2$ & $1-3$ & $1-4$ & $2-3$ & $2-4$ & $3-4$ \\
\hline 1. FEtdu & 10.9 & 4.0 & 4.17 & 0 & & & $* *$ & & & $*$ \\
\hline 2. FEMs & 87.0 & 69.2 & 91.6 & 92.7 & & & & $*$ & $* *$ & \\
\hline 3. FHgsi & 47.8 & 46.2 & 48.6 & 40.2 & & & & & & \\
\hline 4. FHgtr & 6.52 & 0 & 5.56 & 2.44 & & & & & & \\
\hline 5. FRDtr & 6.52 & 7.69 & 25.7 & 17.1 & & $* *$ & & $*$ & & \\
\hline 6. FLTIdu & 6.52 & 26.9 & 9.72 & 18.3 & $*$ & & & $*$ & & \\
\hline 7. FMtlg & 22.2 & 46.2 & 35.7 & 35.4 & $*$ & & & & & \\
\hline 8. FPC (M 2$)$ & 48.8 & 38.5 & 41.4 & 20.7 & & & $* *$ & & & $* *$ \\
\hline 9. FMbac & 16.3 & 19.2 & 22.9 & 26.8 & & & & & & \\
\hline 10. FMbac(-) & 2.33 & 0 & 25.7 & 2.44 & & $* * *$ & & $*$ & & $* * *$ \\
\hline 11. FBsme & 35.3 & 7.69 & 20.6 & 7.32 & & & $*$ & & & \\
\hline 12. FBsla & 34.8 & 23.1 & 30.0 & 53.7 & & & $*$ & & $*$ & $* *$ \\
\hline 13. FAsac & 2.17 & 0 & 0 & 1.22 & & & & & & \\
\hline 14. FMas & 20.0 & 38.5 & 19.4 & 30.5 & & & & & & \\
\hline 15. FPmla & 52.2 & 23.1 & 26.4 & 26.8 & $*$ & $* *$ & $* *$ & & & \\
\hline 16. FFsOcsi & 17.4 & 23.1 & 29.2 & 25.6 & & & & & & \\
\hline
\end{tabular}

Note: WC - Western Caucasus, CC - Central Caucasus. 1 - Upper Lagonaki, 2 - vicinity of the village of Khamyshki, 3 - vicinity of the village of Bezengi, $4-$ vicinity of the city of Nalchik. Significance level of intergroup differences in individual features: $* p<$ $0.5 ; * * p<0.01 ; * * * p<0.001$.

The phenetic distance between the two samples was significant and was $0.0604 \pm 0.0235(\chi 2=29.84$; d.f. $=15$; $\mathrm{p}<0.05$ ) (Table 2). A similar comparison of Central Caucasian samples from two geographic locations, Bezengi and Nalchik, located at approximately the same altitudinal distance from each other, revealed significant differences in the frequencies of four traits: FEtdu, FPC $\left(\mathrm{M}_{2}\right)$, FMbac(-), and FBsla. All noted signs, except for the last one, are reliably more frequent in the sample originating from the highest terrain height. The phenetic distance between these samples was also statistically highly reliable: $\mathrm{MMD}=0.0630 \pm 0.0101(\chi 2=52.68$; d.f. $=15 ; \mathrm{p}<0.001)$ (Table 2). The next stage was a comparison of mid-mountain Central and West Caucasian samples (the vicinity of the Upper Lagonaki plateau and the vicinity of the village of Bezengi). As can be seen from Table 1, the sample from the Central Caucasus is characterized by a significant frequency of occurrence of the traits: FRDtr and FMbac(-), and the Western Caucasus - FPmla. The West Caucasian midmountain sampling (in the vicinity of the Upper Lagonaki Plateau) and the Central Caucasian foothill sampling (around the city of Nalchik) differ even more in the number of characters. Of the five traits that reliably distinguish these samples, four are significantly more frequent in the animals from the vicinity of the Upper Lagonaki plateau. The phenetic distance in both the first and second cases was statistically highly significant: $\mathrm{MMD}=0.0560 \pm 0.0144(\chi 2=40.35$; d.f. $=15$; $\mathrm{p}<0.001)$ and $\mathrm{MMD}=0.0974 \pm 0.0137 \quad(\chi 2 \quad=54.69$; d.f. $=15 ; \mathrm{p}<0.001)$ respectively.

Table 2. Phenetic distances (MMD) on the complex of traits (upper triangular matrix) between samples of wood mice A. uralensis of Western and Central Caucasus, mean standard deviations - MSD (lower triangular matrix) and estimates of mean uniqueness (MMU) of samples

\begin{tabular}{|l|l|l|l|l|l|}
\hline \multirow{2}{*}{ Samples } & \multicolumn{3}{c|}{ Location of material collection } & \multirow{2}{*}{ MMU } \\
\cline { 2 - 5 } & WC & WC & CC & CC & \\
\cline { 2 - 5 } & 1 & 2 & 3 & 4 & \\
\hline 1. Upper Lagonaki (WC) & & 0.0604 & 0.0560 & 0.0974 & 0.0713 \\
\hline 2. Vicinity of the Khamyshki village (WC) & 0.0235 & & 0.0670 & 0.0303 & 0.0526 \\
\hline 3. Vicinity of the Bezengi village (CC) & 0.0144 & 0.0199 & & 0.0630 & 0.0620 \\
\hline 4. Vicinity of the Nalchik city (CC) & 0.0137 & 0.0192 & 0.0101 & & 0.0636 \\
\hline
\end{tabular}


Differences not exceeding the first level of significance were found when comparing piedmont samples from the Western and Central Caucasus (Khamyshki and Nalchik districts): $\mathrm{MMD}=0.0303 \pm 0.0192\left(\chi^{2}=26.60\right.$; d.f. $\left.=15 ; \mathrm{p}<0.05\right)$. At the same time, the sample from Nalchik vicinity is characterized by significantly high frequency of occurrence of two features FEMs and FBsla in comparison with the sample from Khamyshki vicinity.

Of all the samples, the mean sample from the vicinity of the Upper Lagonaki plateau is the most phenetically unique.

\section{Intraspecific differentiation of A.flavicollis}

The results of comparison of western and eastern Caucasian samples shown in Table 3 show the following picture. The phenetic distances between all pairs of compared samples were reliable and ranged from 0.0328 to 0.111 . However, a greater phenetic similarity with each other is shown by plain samples from the Krasnodar Territory and the Eastern Caucasus: Golovinka - Bilbil-Kazmalyar: MMD $=0.0328 \pm 0.0173$, as well as middle-mountain and foothill samples from the Republic of Adygea: Upper Lagonaki - Khamyshki: $\mathrm{MMD}=0.0455 \pm 0.0208$.

Table 3. Phenetic distances (MMD) for a set of traits (upper triangular matrix) between population samples of wood mice A. flavicollis of the Western and Eastern Caucasus, mean standard deviations - MSD (lower triangular matrix) and estimates of mean uniqueness (MMU) of samples

\begin{tabular}{|c|c|c|c|c|c|}
\hline \multirow{3}{*}{ Samples } & \multicolumn{4}{|c|}{ Location of material collection } & \multirow[t]{2}{*}{ MMU } \\
\hline & WC & WC & WC & $\mathrm{EC}$ & \\
\hline & 1 & 2 & 3 & 4 & \\
\hline 1. Upper Lagonaki (WC) & & 0.0455 & 0.0664 & 0.111 & 0.0743 \\
\hline 2. Vicinity of the Khamyshki village (WC) & 0.0207 & & 0.1007 & 0.0773 & 0.0743 \\
\hline 3. Vicinity of the Golovinka village (WC) & 0.0241 & 0.0140 & & 0.0328 & 0.0664 \\
\hline 4. Vicinity of the Bilbil-Kazmalyar village (EC) & 0.0241 & 0.0140 & 0.0173 & & 0.0737 \\
\hline
\end{tabular}

Note: WC - Western Caucasus, EC - Eastern Caucasus. MMU - average uniqueness of samples.

Significant differences between the Upper Lagonaki and Khamyshki samples are noted for two traits FEtdu and FMas, which are significantly more frequent in the sample from the Upper Lagonaki plateau. Also by two characters (FMtlg and FPC $\left(\mathrm{M}_{2}\right)$ ), the Golovinka Bilbil-Kazmalyar samples differ. Both traits are more frequent in the conditions of the Eastern Caucasus.

Table 4. Frequencies of non-metric trait in A. flavicollis in the Western and Eastern Caucasus

\begin{tabular}{|l|l|l|l|l|l|l|l|l|l|l|}
\hline \multirow{2}{*}{ Traits } & WC & WC & WC & \multicolumn{2}{c|}{ EC } & \multicolumn{7}{c|}{$\chi^{2}$} \\
\cline { 2 - 14 } & 1 & \multicolumn{1}{c|}{2} & \multicolumn{1}{c|}{3} & 4 & $1-2$ & $1-3$ & $1-4$ & $2-3$ & $2-4$ & $3-4$ \\
\hline 1. FEtdu & 15.4 & 1.35 & 0 & 0 & $*$ & $* *$ & $* *$ & & & \\
\hline 2. FEMs & 100 & 100 & 100 & 100 & & & & & & \\
\hline 3. FHgsi & 26.9 & 17.6 & 27.3 & 22.7 & & & & & & \\
\hline 4. FHgtr & 11.5 & 9.46 & 0 & 0 & & $*$ & $*$ & $*$ & $*$ & \\
\hline 5. FRDtr & 7.69 & 1.43 & 2.27 & 0 & & & & & & \\
\hline 6. FLTIdu & 0 & 2.70 & 2.27 & 2.27 & & & & & & \\
\hline 7. FMtlg & 26.9 & 29.7 & 20.5 & 40.9 & & & & & & $*$ \\
\hline 8. FPC (M 2$)$ & 15.4 & 24.3 & 9.09 & 47.7 & & & $* *$ & $*$ & $*$ & $* * *$ \\
\hline 9. FMbac & 12.0 & 21.6 & 27.3 & 20.5 & & & & & & \\
\hline 10. FMbac(-) & 4.0 & 5.41 & 0 & 0 & & & & & & \\
\hline 11. FBsme & 30.0 & 18.2 & 4.55 & 9.09 & & & & & & \\
\hline 12. FBsla & 53.9 & 44.6 & 50.0 & 34.1 & & & & & & \\
\hline 13. FAsac & 0 & 0 & 2.27 & 4.55 & & & & & & \\
\hline 14. FMas & 53.9 & 13.5 & 65.9 & 52.3 & $* * *$ & & & $* * *$ & $* * *$ & \\
\hline 15. FPmla & 50.0 & 64.9 & 77.3 & 84.1 & & $*$ & $* *$ & & $*$ & \\
\hline 16. FFsOcsi & 23.1 & 25.7 & 34.1 & 34.1 & & & & & & \\
\hline
\end{tabular}

Note: WC - Western Caucasus: 1 - vicinity of Upper Lagonaki plateau, 2 - vicinity of Khamyshki village, 3 - vicinity of Golovinka settlement; EC - Eastern Caucasus: 4 - vicinity of Bilbil-Kazmalyar village. Significance level of intergroup differences in individual features: $* p<0.5 ; * * p<0.01 ; * * *<<0.001$. 
When comparing a sample from the Upper Lagonaki Plateau area with two flat samples (Golovinka, BilbilKazmalyar), differences are noted practically for the same characters: FEtdu, FHgtr, and FPmla. It should be noted that the first two traits are found only in the sample from the midlands and are absent in the plain samples. On the contrary, the occurrence of the latter trait is higher in the flat samples compared to the middle samples. The phenetic distance between Upper Lagonaki - Golovinka samples does not exceed the first level of significance and is: $\mathrm{MMD}=0.0664 \pm 0.0241(\chi 2=30.47$; d.f. $=15 ; \mathrm{p}<0.05)$, this is almost 1.7 times the distance between Upper Lagonaki and Bilbil-Kazmalyar samples: $\mathrm{MMD}=0.111 \pm 0.0241(\chi 2=44.12 ;$ d.f. $=15 ; \mathrm{p}<0.001)$. The foothill sample (around the village of Khamyshki) also differs from the two plain samples by the same traits FHgtr, FPC $\left(\mathrm{M}_{2}\right)$, and FMas. As noted earlier, the trait FHgtr is absent in the plain samples, while the trait FMas, on the contrary, is significantly more frequently noted in the plain conditions. The character of manifestation of the FPC $\left(\mathrm{M}_{2}\right)$ trait in the two plain samples is different. As can be seen in the sample from East Caucasus (neighborhood of Bilbil-Kazmalyar) occurrence of this feature is reliably higher than in all other samples, while in the sample from Golovinka lower, but reliably only relative to samples from neighborhood of Khamyshki and Bilbil-Kazmalyar. The distances obtained between samples Khamyshki Golovinka and Khamyshki - Bilbil-Kazmalyar are also statistically highly reliable: $\mathrm{MMD}=0.101 \pm 0.0140$ $(\chi 2=59.73 ;$ d.f. $=15 ; \mathrm{p}<0.001)$ and $\mathrm{MMD}=0.0773 \pm 0.0140$ $(\chi 2=50.75 ;$ d.f. $=15 ; \mathrm{p}<0.001)$ respectively.

In populations of $A$. flavicollis, the average measure of phenetic uniqueness is approximately the same.

\section{Interspecies comparison}

Comparison of two cryptic species of A. uralensis and $A$. flavicollis occurring symbiotopically in the Western Caucasus (Upper Lagonaki plateau) revealed differences in frequencies of only 3 characters of 16 - FEMs, $\mathrm{FPC}\left(\mathrm{M}_{2}\right)$, FMas, these characters except for $\mathrm{FPC}\left(\mathrm{M}_{2}\right)$ occur significantly more often in A. flavicollis (Tables 1 , 4-5). The phenetic distance between the marked species was $\mathrm{MMD}=0.261 \pm 0.0245\left(\chi_{2}=87.86\right.$; d.f. $\left.=15 ; \mathrm{p}<0.001\right)$. As noted earlier, the Lagonaki plateau was conventionally divided into Lower and Upper Lagonaki, respectively, it seemed interesting to compare two species occurring separately: A. uralensis (Lower Lagonaki plateau) and $A$. flavicollis (Upper Lagonaki plateau). The distance $\left(\mathrm{MMD}=0.340 \pm 0.0216\left(\chi^{2}=116.56\right.\right.$; d.f. $\left.\left.=15 ; \mathrm{p}<0.001\right)\right)$ obtained in this comparison variant was 1.3 times higher than that found in the symbiotopic zone.

The distance between A. uralensis and A. flavicollis, but from another geographical point of the Western Caucasus, around the village of Khamyshki, was somewhat higher: $\mathrm{MMD}=0.299 \pm 0.0198 \quad\left(\chi^{2}=109.7\right.$; d.f. $=15 ; \mathrm{p}<0.001)($ Table 6$)$. In this case, differences are revealed for 5 traits out of 16, of which FEMs, FPmla with high frequency are found in A. flavicollis, and FHgsi, FLTIdu, FMas in A. uralensis. The set of characters distinguishing these taxa in the conditions of the Upper Lagonaki Plateau and Khamyshki village coincides with two characters - FEMs and FMas. However, the frequency of the latter trait is higher for A. flavicollis in mid-mountain conditions and for A. uralensis in foothills. Nevertheless, given that the samples of these species come from the same biotopes, it can be assumed that the observed differences in the occurrence of phenes reflect rather species-specific features of the groups studied.

Table 6. Phenetic distances and mean standard deviations (MMD \pm MSD) between twin species of genus Apodemus of the Western and Eastern Caucasus

\begin{tabular}{|l|c|c|c|c|}
\hline \multicolumn{1}{|c|}{ Species } & $\begin{array}{c}\text { Vicinity of Upper } \\
\text { Lagonaki plateau } \\
\text { A. flavicollis } \text { (WC) }\end{array}$ & $\begin{array}{c}\text { Vicinity of } \\
\text { Khamyshki village } \\
\text { A. flavicollis (WC) }\end{array}$ & $\begin{array}{c}\text { Vicinity of } \\
\text { Golovinka settlement } \\
\text { A. flavicollis (WC) }\end{array}$ & $\begin{array}{c}\text { Vicinity of Bilbil- } \\
\text { Kazmalyar village } \\
\text { A. flavicollis (EC) }\end{array}$ \\
\hline $\begin{array}{l}\text { Vicinity of Upper } \\
\text { Lagonaki plateau } \\
\text { A. uralensis (WC) }\end{array}$ & $0.261 \pm 0.0245$ & $0.324 \pm 0.0143$ & $0.433 \pm 0.0176$ & $0.368 \pm 0.0176$ \\
\hline $\begin{array}{l}\text { Vicinity of Khamyshki } \\
\text { village } \\
\text { A. uralensis } \text { (WC) }\end{array}$ & $0.239 \pm 0.0299$ & $0.299 \pm 0.0198$ & $0.320 \pm 0.0231$ & $0.283 \pm 0.0231$ \\
\hline $\begin{array}{l}\text { Vicinity of Bezengi } \\
\text { village } \\
\text { A. uralensis (CC) }\end{array}$ & $0.374 \pm 0.0209$ & $0.437 \pm 0.0107$ & $0.565 \pm 0.0141$ & $0.533 \pm 0.0141$ \\
\hline $\begin{array}{l}\text { Vicinity of city Nalchik } \\
\text { A. uralensis (CC) }\end{array}$ & $0.365 \pm 0.0201$ & $0.432 \pm 0.010$ & $0.427 \pm 0.0133$ & $0.471 \pm 0.0133$ \\
\hline
\end{tabular}

When analyzing the interspecific phenetic distances obtained when comparing two species from different geographical locations, it is well seen that minimal differences are observed when comparing the Western Caucasian sample of $A$. uralensis from the Khamyshki settlement area with $A$. flavicollis from the BilbilKazmalyar settlement area. Notably, the distance $\mathrm{MMD}=0.283 \pm 0.0231 \quad(\chi 2=92.2 ;$ d.f. $=15 ; \mathrm{p}<0.001)$ obtained is close to that found between species in the symbiotopic zone. Populations of two species of $A$. uralensis (Khamyshki and A. flavicollis (Golovinka) are phenetically distant to a slightly greater extent $\mathrm{MMD}=0.320 \pm 0.0232(\chi 2=101.8 ;$ d.f. $=15 ; \mathrm{p}<0.001)$. The Lagonak population of $A$. uralensis also differs significantly from the populations of $A$. flavicollis both from the Bilbil-Kazmalyar settlement and from the vicinity of Golovinka. In the first case, differences were revealed for 5 non-metric features - FEtdu, FEMs, 
FHgsi, FMas, FPmla; in the second case, in addition to the noted five, two more features - FPC $\left(\mathrm{M}_{2}\right)$ and FBsme. The distance obtained between populations of the two species was $\mathrm{MMD}=0.368 \pm 0.0176(\chi 2=146.0$; d.f. $=15 ; \mathrm{p}<0.001)$ and $\mathrm{MMD}=0.433 \pm 0.176(\chi 2=166.2$; d.f. $=15 ; \mathrm{p}<0.001)$.

Comparison of the occurrence of phenes in twin species originating from the Western and Central Caucasus A. flavicollis (Upper Lagonaki Pl.) and $A$. uralensis (Bezengi village) revealed reliable differences in 7 characters: FEMs, FRDtr, FPC $\left(\mathrm{M}_{2}\right), \operatorname{FMbac}(-)$, FBsla, FMas, and FPmla. The populations of $A$. flavicollis (Upper Lagonaki Pl.) and A. uralensis (Nalchik) differ in five characters, while coincidence with the above population pair is noted for three ones: 2 , 14,15 . The distance in the first case was $0.374 \pm 0.0209$, and in the second $0.365 \pm 0.0201$. Approximately similar value of the measure of differentiation is observed when comparing the western Caucasian sample of $A$. flavicollis (Khamyshki village) with the central Caucasian A. uralensis (Bezengi and Nalchik): $0.437 \pm 0.0107$ and $0.432 \pm 0.010$, respectively. Analysis of the occurrence of phenes revealed reliable differences in 6 traits, both between samples of A. flavicollis (Khamyshki village) - A. uralensis (Bezengi), and between $A$. flavicollis (Khamyshki village) $-A$. uralensis (Nalchik). It should be noted that the frequency of occurrence of most features is higher in $A$. uralensis than in A. flavicollis (Table 5). A. flavicollis from the Golovinka settlement area and $A$. uralensis from the Bezengi village area show even more differences in the number of characters. As shown in Table 1, 4-5 differences are found for $50 \%$ of the traits. A. uralensis is characterized by a high frequency of the traits FHgsi, FRDtr, $\operatorname{FPC}\left(\mathrm{M}_{2}\right)$, and $\operatorname{FMbac}(-)$; in $A$. flavicollis, such traits are FEMs, FBsla, FMas, and FPmla. The phenetic distance was significant: $\mathrm{MMD}=0.565 \pm 0.0141 \quad(\chi 2=262.3 ;$ d.f. $=15 ; \mathrm{p}<0.001)$ (Table 6), but despite this distance did not exceed the level of subspecies differences. The differences between A. flavicollis (Golovinka) and A. uralensis (Nalchik) are less pronounced (31\% of features). The level of their isolation is $0.427 \pm 0.013$.

\section{Conclusion}

Based on the results of the morphological analysis of the populations of two cryptic species, we can conclude the following. When comparing intraspecific samples of $A$. uralensis from the Central and Western Caucasus, the minimum distance of 0.0303 was found when comparing the pair of samples of Khamyshki - Nalchik originating from the foothills. The distance between a pair of mid-mountain samples of the Central and Western Caucasus (Upper Lagonaki - Bezengi) is somewhat higher. The phenotypic differences between mid-mountain and foothill samples of $A$. uralensis are more pronounced, and these differences are amplified when comparing samples from the Western and Central Caucasus (MMD=0.0974), but no change in phenotype frequencies associated with terrain elevation gradient is observed. None of the features distinguishing midmountain and foothill samples (both in the Western and Central Caucasus) was found to coincide.

Calculation of phenetic distances according to the complex of characters for the species A. flavicollis revealed the greatest similarity between the two plain samples from the Western and Eastern Caucasus (Golovinka - Bilbil-Kazmalyar). In general, the plain samples, as compared to the mid-mountain and foothill samples, are characterized by the complete absence of a number of traits - Fetdu, FHgtr and FMbac(-). The frequencies of most traits differ little in the two plain samples. Nevertheless, the population from the Eastern Caucasus stands out among all samples by the high frequency of traits 7 and 8 . In A. flavicollis, the maximum differences are also observed between the extreme samples: midland and plain. In contrast to $A$. uralensis, in A. flavicollis there is a clearer pattern in the manifestation of a number of characters. Thus, the middle-mountain sample is characterized by a high frequency of features 1 and 4 as compared with the plain sample. In the foothill sample, trait 4 can be considered as such. In interspecific comparisons, minimal distance was found between cryptic species inhabiting symbiotopically and sympatrically in the Western Caucasus, in particular in the Republic of Adygea (plateaus Upper Lagonaki and Khamyshki). In the first geographic point the distance between species was $0.261 \pm 0.0245$ and in the second $0.298 \pm 0.0198$ (Table 9). In this case, the lower value of phenotypic differences is probably due to the habitat of both species in similar landscape-biotopic and climatic conditions, which contributes to the development of phenotypic similarity.

The maximum MMD value was found when comparing $A$. uralensis of the Central Caucasus (Bezengi) and A. flavicollis of the West Caucasus (Golovinka). In general, the Bezengi population of $A$. uralensis appears to be more differentiated from all the populations of $A$. flavicollis under consideration.

Some differences in the frequencies of the traits in the two species are noteworthy. A. flavicollis in both the Western and Eastern Caucasus are characterized by $100 \%$ occurrence of the trait - a foramen in the mastoid bone. The populations of $A$. uralensis differ markedly from $A$. flavicollis in the frequency of occurrence of characters 3 and 5. The occurrence of trait 3 is higher in all populations of $A$. uralensis, and trait 5 only in the Central Caucasus populations.

Thus, the distance obtained between two sympatrically and symbiotopically occurring species is only 2 or more times higher than the maximum intraspecific distance. The highest value $\mathrm{MMD}=0.563$ obtained between geographically separated taxa $A$. uralensis and $A$. flavicollis exceeds the intraspecific value more than 5 times, nevertheless, the revealed differences do not exceed the level of subspecies differences, according to the gradations proposed for small murine rodents [18]. Our results indicate 
significant morphological similarity of the studied species according to the studied phenetic characters (cranial foramen), although according to the results of molecular genetic analysis of the cyt $b$ gene site, the genetic distance between the taxa is $10 \%$, which according to the literature corresponds to the level of interspecific differences $[6,32]$.

In connection with the above, the use of morphological parameters in the diagnosis of the studied species in the Caucasus is not possible even with statistically significant differences. Reliable diagnosis of cryptic species of the genus Apodemus of the North Caucasus is possible only by molecular genetic methods.

\section{References}

1. E.A. Koblic, Ya.A. Redkin, V.Yu. Arkhipov, Cheklist of the birds of Russian Federation (Moscow: KMK Scientific Press Ltd, 2006)

2. N.M. Sukhikh, Abstract PhD Thesis. St. Petersburg (2013)

3. G.N. Chelomina, M.V. Pavlenko, I.V. Kartavtseva, G.G. Boeskorov, E.A. Lyapunova, N.N. Vorontsov, Russ. J. Genet., 34(2), 213 - 225 (1998)

4. G.N. Chelomina, D.M. Atopkin, A.S. Bogdanov, Doklady Biological Sciences, 416(1), 356-359 (2007)

5. G.N. Chelomina, D.M. Atopkin, J. Mol. Biol., 44(5), 792-803 (2010)

6. G.N. Chelomina, Wood and field mice: Moleculargenetic aspects of evolution and systematics (Vladivostok, Dalnauka, 2005)

7. M.I. Baskevich, Trudy II regional'noi konf. (Biological Diversity of the Caucasus: Proc. II Regional Conf.), (Sukhum, 2002)

8. A.S. Bogdanov, Russ. J. Genet., 40(8), 1099-1112 (2004)

9. A.S. Bogdanov, D.M. Atopkin, G.N. Chelomina, J. Biology Bulletin, 36(3), 227-241 (2009)

10. A.S. Bogdanov, V.V. Stakheev, A.E. Zykov, V.V. Yakimenko, M.G. Malkova, Russ. J. Genet., 48(2), 186-192 (2012)

11. A.E. Balakirev, M.I. Baskevich, A.P. Gmyl, N.M. Okulova, T.A. Andreeva, O.V. Sokolenko, V.M. Malygin, L.A. Khlyap, M.L. Oparin, V.N. Orlov, Russ. J. Genet., 43(12), 1651-1666 (2007)

12. J.R. Michaux, P. Chevret, M.G. Filippucci, M. Macholán, Mol. Phylogenet. Evol., 23(2), 123-136 (2002)

13. J.R. Michaux, R. Libois, M.G. Filippucci, Heredity, 94(1), 52-63 (2004)

14. J. Darvish, Z. Mohammadi, F. Ghorbani, A. Mahmoudi, S. Dubey, J. Mamm. Evol., 22(4), 1-13 (2015)
15. F.A. Tembotova, M.V. Kholodova, A.Kh. Amshokova, E.A. Kuchinova, Proc. IV Int. Conf., (Nalchik, 2012)

16. A.Kh. Amshokova, F.A. Tembotova, E.A. Kuchinova, Izvestiya Samarskogo nauchnogo tsentra Rossiyskoy akademii nauk, 17(4-2), 402$412(2015)$

17. A.V. Yablokov, N.I. Larina, Introduction to phenetics populations: A new approach to studying natural populations (Moscow, 1985)

18. A.G. Vasil'ev, I.A. Vasil'eva, V.N. Bol'shakov, Evolutionary and ecological analysis of stability of population structure of a species (chronogeographical approach) (Yekaterinburg: Yekaterinburg Publishing House, 2000).

19. R.J. Berry, Evolution, 18(3), 468-483 (1964)

20. R.J. Berry, Biol. J. Lin. Soc., 28, 205-230 (1986)

21. T. Sjøvold, Non-metrical divergence between skeletal populations. The theoretical foundation and biological importance of C.A.B. Smith's Mean Measure of Divergence (Ossa, 1977)

22. S.E. Hartman, J. Mammal, 61(3), 436-448 (1980)

23. I.A. Vasil'eva, A.G. Vasil'ev, V.N. Bolshakov, Archives of the zoological museum of Moscow state university (Moscow: Moscow Univ. Publ., 2008)

24. V.E. Sokolov, A.K. Tembotov, The Vertebrates of the Caucasus. Mammals. Insectivora. (Moscow: Nauka, 1998)

25. A.K. Tembotov, E.A. Shebzukhova, F.A. Tembotova, A.A. Tembotov, I.L. Vorokova, Problems of ecology of mountain areas (Maykop, 2001)

26. A.G. Vasil'ev, I.A.Vasil'eva, V.N. Bol'shakov, Russ. J. Ecol., 27(2), 113-120 (1996)

27. A.G. Vasil'ev, Epigenetic basis of phenetics: on the way to population meronomy (Yekaterinburg: Akademkniga, 2005)

28. V.N. Peskov, I.G. Emel'yanov, Vestn. Zool., 3, 3944 (2000)

29. I.A.Vasil'eva, A.G. Vasil'ev, N.M. Lyubashevskii, M.V. Chibiryak, E.Yu. Zakharova, O.V. Tarasov, Russ. J. Ecol., 34(6), 405-412 (2003)

30. A.G. Vasil'ev, I.A. Vasil'eva, Homological Variation of Morphological Structures and Epigenetic Divergence of Taxa: Bases of Population Meronomy), (Moscow: KMK, 2009)

31. A.G. Vasil'ev, Application package of PHEN 3 programs. URL: (http://ecoinf.uran.ru) (1995)

32. Y. Martin, G. Gerlach, C. Schlötterer, A. Meyer, Molecular Phylogenetics and Evolution, 16, 37-47 (2000) 
Table 5. Differences in the frequencies of non-metric trait in A. uralensis and A. flavicollis in the Northern Caucasus

\begin{tabular}{|c|c|c|c|c|c|c|c|c|c|c|c|c|c|c|c|c|}
\hline \multirow{2}{*}{ Trait } & \multicolumn{16}{|c|}{$\chi^{2}$} \\
\hline & $1-5$ & $1-6$ & $1-7$ & $1-8$ & $2-5$ & $2-6$ & $2-7$ & $2-8$ & $3-5$ & $3-6$ & $3-7$ & $3-8$ & $4-5$ & $4-6$ & $4-7$ & $4-8$ \\
\hline 1. FEtdu & & $*$ & $*$ & $*$ & & & & & & & & & $* *$ & & & \\
\hline 2. FEMs & $* * *$ & $* * *$ & $* * *$ & *** & $* * *$ & $* * *$ & $* * *$ & $* * *$ & $* * *$ & $* * *$ & $* * *$ & $* * *$ & $* * *$ & $* * *$ & $* * *$ & $* * *$ \\
\hline 3. FHgsi & & $* * *$ & $*$ & * & & $* *$ & & $*$ & & $* * *$ & $* *$ & $* *$ & & $* *$ & & * \\
\hline 4. FHgtr & & & & & & & & & & & & & & & & \\
\hline 5. FRDtr & & & & & & & & & * & $* * *$ & $* * *$ & $* * *$ & & $* * *$ & $* *$ & $* * *$ \\
\hline 6. FLTIdu & & & & & $* *$ & $* * *$ & $* *$ & $* *$ & & & & & $* *$ & $* * *$ & $* *$ & $* *$ \\
\hline 7. FMtlg & & & & & & & * & & & & & & & & & \\
\hline 8. $\mathrm{FPC}\left(\mathrm{M}_{2}\right)$ & ** & ** & $* * *$ & & & & $* *$ & & * & * & $* * *$ & & & & & $* *$ \\
\hline 9. FMbac & & & & & & & & & & & & & & & & \\
\hline 10. FMbac(-) & & & & & & & & & * & $* * *$ & $* * *$ & $* * *$ & & & & * \\
\hline 11. FBsme & & & * & & & & & & & & & & & & & \\
\hline 12. FBsla & & & & & * & & * & & * & & * & & & & & \\
\hline 13. FAsac & & & & & & & & & & & & & & & & \\
\hline 14. FMas & $* *$ & & $* * *$ & $* *$ & & $*$ & * & & $*$ & & $* * *$ & $* * *$ & * & * & $* * *$ & * \\
\hline 15. FPmla & & & $* *$ & $* *$ & $*$ & $* *$ & $* * *$ & $* * *$ & $*$ & $* * *$ & $* * *$ & $* * *$ & * & $* * *$ & $* * *$ & $* * *$ \\
\hline 16. FFsOcsi & & & & & & & & & & & & & & & & \\
\hline
\end{tabular}

Note: A. uralensis: 1 - vicinity of Upper Lagonaki plateau, 2 - vicinity of Khamyshki village, 3 - vicinity of the village of Bezenghi, 4 - vicinity of the city of Nalchik; A. flavicolli: 5 - vicinity of Upper Lagonaki plateau, 6 - vicinity of Khamyshki village, 7 - vicinity of Golovinka settlement, 8 - vicinity of Bilbil-Kazmalyar village. Significance level of intergroup differences in individual features: $* p<0.5 ; * * p<0.01 ; * * * p<0.001$. 